\title{
Prediction of Spatiotemporal Invasive Risk by the Red Imported Fire Ant (Hymenoptera: Formicidae) in South Korea
}

\author{
Dae-hyeon Byeon ${ }^{1}$, Jong-Ho Lee ${ }^{2}$, Heung-Sik Lee ${ }^{2}$, Youngjin Park ${ }^{3}$, Sunghoon Jung ${ }^{4}$ and \\ Wang-Hee Lee ${ }^{1, *}$ \\ 1 Department of Biosystems Machinery Engineering, Chungnam National University, Daejeon 34134, Korea; \\ bdh0735@naver.com \\ 2 Plant Pest Control Division, Plant Quarantine Department, Animal and Plant Quarantine Agency, \\ Gimcheon 39660, Korea; acarologist@korea.kr (J.-H.L.); lhsgo@korea.kr (H.-S.L.) \\ 3 Plant Quarantine Technology Center, Animal and Plant Quarantine Agency, Gimcheon 39660, Korea; \\ parky1127@korea.kr \\ 4 Department of Applied Biology, Chungnam National University, Daejeon 34134, Korea; jung@cnu.ac.kr \\ * Correspondence: wanghee@cnu.ac.kr; Tel.: +82-42-821-6720
}

Received: 21 May 2020; Accepted: 17 June 2020; Published: 19 June 2020

\begin{abstract}
In this study, we analyzed the potential distribution of red imported fire ant, Solenopsis invicta Buren (Hymenoptera: Formicidae), in response to climate change in South Korea using CLIMEX, a species distribution model. We further attempted to evaluate the risk of the distribution/invasion and subsequent dispersion by considering climatic suitability, and functional characteristics of cities and covered cultivated areas. The climatic suitability has extended from the southern and coastal regions to inland regions due to climate change. The number of areas with EI (Ecoclimatic Index) values of more than 20 was $9(12 \%)$ in the current climate; the value was assumed to increase to $23 \%$ (2040), 24\% (2060), 42\% (2080), and 62\% (2100) from the South Korea coast to inland. We predicted that May to October would be the most active period in seven domestic high-habitation areas. We also analyzed the invasive risk of the red imported fire ant into covered domestic cultivation areas. Considering climatic suitability, we determined that Jeju, Pohang, Busan, Ulsan, Mokpo, and Gosan would be the most affected areas. This study can provide baseline data for the management of invasive species nationally and for regional control through predictions of the probability of settlement and direction of spread.
\end{abstract}

Keywords: climatic suitability; CLIMEX; digital mapping; potential distribution; invasive-risk analysis

\section{Introduction}

Although there are different factors affecting insect distribution [1], the climate is considered the most influential factor [2-5]. Therefore, many studies that examined the effects of climate change on pest distribution [6-8] or predicted invasion risk and potential pest distribution [9-11] use climate as the primary variable. CLIMEX is software that implements species distribution modeling [12]. It estimates bioclimatic parameters of target species by dominantly considering meteorological data to develop niche models; and it provides approximations for early monitoring reports and decision making in pest control [1,4]. Its application has been expanded to various pests in many countries [13]. South Korea is a recent region to use CLIMEX for predicting the potential distribution of invasive pests since climate change has increased the risk of invasion [14-20].

The Intergovernmental Panel on Climate Change (IPCC) proposed that global warming might shift species distribution [21]. Many reports have recently covered the introduction of alien species into 
new areas. As a result of climate change, South Korea has also suffered nationwide damage caused by the introduction of invasive species [22]; the risk of new invasion is unfortunately increased by the accelerating climate change. Amongst new threats by invasive species, the red imported fire ant (Solenopsis invicta) is one of the biggest concerns in South Korea. This is because the red imported fire ant has caused severe damage to many aspects of human life and wildlife [23], various damages in agriculture [24-26], and even human health due to its aggressiveness and toxicity [27,28]. In addition, its rapid establishment and dispersion necessitate costly control measures that have not yet been completely effective, although various control treatments have been proposed [29,30]. Consequently, significant damage is expected once the ant becomes prominent in South Korea. Since the discovery of Solenopsis invicta in South Korea in 2017 and 2018, it has been recognized that developing an early monitoring system and management policy will be necessary.

Species distribution modeling is an effective method of providing fundamental background for developing such an early monitoring system and assessing the region of focus. The potential expansion range of the red imported fire ant was predicted by a dynamic model of colony growth based on climate data in the US [31] and the world [32]. In 2005, Sutherst and Maywald [33] used CLIMEX software to evaluate the potential distribution of red imported fire ant in the US and Oceania. Potential distribution of the red imported fire ant was predicted in South Korea by using a machine-learning-based statistical approach but this study used only distribution data [34]. There are other factors that induce invasion of red imported fire and determine their domestic establishment. Therefore, this study aims to analyze the invasive risk of the red imported fire ant based on climatic suitability, regional characteristics and the effect of agricultural facilities, which allow the red imported fire ant to endure unfavorable climate. To accomplish the study objectives, we first evaluated climatic suitability and predicted potential seasons for the red imported fire ant activity based on the characteristics of cities having high climatic suitability. Then, protected/covered cultivation areas were incorporated within the climatic suitability map to estimate the most vulnerable areas exposed to the red imported fire ant invasion and establishment.

\section{Materials and Methods}

\subsection{Distribution Data of the Red Imported Fire Ant}

The red imported fire ant is considered to have originated from Pantanau regions (Swampy areas) covering Brazil, Paraguay, and northern Argentina, and ten migrated to Texas, Louisiana, Mississippi, Georgia, and Florida in the 1930s [35]. It is now known to be widely distributed from Oklahoma and Northern California to Virginia [30,33,36-38]. The red imported fire ant was also found in Australia, New Zealand, and Taiwan in 2003, and in Mainland China in 2004 [39-42]. In South Korea, its invasion was first reported in Busan, in 2017; it was subsequently found in Daegu in 2018 [43]. Distribution data were obtained from the CABI (Centre for Agriculture and Bioscience International; data by states) and GBIF (Global Biodiversity Information Facility; data by occurrence coordinates) public databases, defined in parameters of latitude and longitude [44,45]. The acquired data were projected onto a world map using ArcMap (version 10.4.1, ESRI, Redland, CA, USA). Data from the two databases had a similar global distribution and consistent with the distribution of red imported fire ant found in previous studies [32]. The developed distribution database and map were used to estimate optimal parameter values and validate the model in Section 2.3 so that the subsequent simulation would show the best fit to the current distribution [12,13].

\subsection{Meteorological Data}

Similar to previous laboratory studies [5,17-19], for climate data of South Korea, we used average daily maximum and minimum temperatures, precipitation and relative humidity at 9:00 a.m. and 3:00 p.m. for the past 30 years (1981-2010) measured at 74 observation stations under the Korea Meteorological Administration (KMA) because they are required to run the CLIMEX model [12]. 
The resulting data were converted into a climate-database format required by the CLIMEX software, with coordinates of 74 stations and averaged monthly values of the above meteorological data. For the climate change scenario, an RCP (Representative Concentration Pathway) of 8.5 was obtained from the KMA and converted into a suitable format in CLIMEX using MATLAB (version 2016a, The Mathworks, Inc., Natick, MA, USA). The constructed databases of an RCP 8.5 climate change scenario generated data estimates from 2040 to 2100, for every 20 years, with high resolution $(1 \mathrm{~km})$ suited for simulating South Korea [5,17-19]. The resulting climate-change-scenario database was composed of more than 97,000 coordinates and allowed high-density simulation for predicting the future distribution of red imported fire ant.

\subsection{Parameter Estimation}

Since CLIMEX connects climate in a specific region with biological characteristics of a target species, assessment of climatic suitability requires intensive estimation of parameters [12,13]. The initial values for model parameters were measured by three methods. The derived optimum parameters were combined to produce the best-fit simulation to the known distribution of red imported fire ant. The first method was to adopt CLIMEX parameter values from a previous study by Sutherst and Maywald [33]. The second used published observations from rearing experiments and seasonal variances such as temperature-dependent developmental rate [46], temperature-dependent survival rate [47], temperature-dependent metabolic activity [48], colony size at different temperatures [49], and survival rate related to soil moisture [50] that were subjected to statistical analysis. Based on these analyses, we determined the limiting low temperature $\left(14.8^{\circ} \mathrm{C}\right)$, lower and upper optimal temperatures $\left(22\right.$ and $\left.37^{\circ} \mathrm{C}\right)$, limiting high temperature $\left(40^{\circ} \mathrm{C}\right)$, and degree-days (476). Low and high soil-moisture limits were set to 0.25 and 2, respectively, while upper and lower optimal-soil moistures were determined to be 1 and 1.5, respectively. The dry- and wet-stress rates were determined to be 0.026 and 0.0088 , respectively, based on the survival rate and time exposure to specific soil moisture [50]. Cold- and heat-stress temperature thresholds were set at $10{ }^{\circ} \mathrm{C}$ and $40{ }^{\circ} \mathrm{C}$, respectively, outside of which most previous studies could not observe red imported fire ant activity $[47,49,51]$. As the last method, we chose parameter values so that the simulation could produce the best fit for distribution in areas of origin, an approach that is commonly used in CLIMEX modeling [12]. None of the methods could exactly match the current distribution in the US where the distribution of red imported fire ant was the most detailed [52]. This suggested the need for further fine-tuning of parameter values. However, after repeated adjustment of parameter values incorporating the three methods, we finally determined optimal values of CLIMEX parameters with the least error in simulating the current distribution in the US at this time. The final parameter values used for predicting the potential distribution of red imported fire ant in South Korea are summarized in Table 1.

Table 1. Optimal values for CLIMEX parameters for red imported fire ant.

\begin{tabular}{llc}
\hline \multicolumn{1}{c}{ Parameters } & Code & Optimal Value \\
\hline Temperature & & \\
\hline Limiting low temperature $\left({ }^{\circ} \mathrm{C}\right)$ & DV0 & 15 \\
Lower optimal temperature $\left({ }^{\circ} \mathrm{C}\right)$ & DV1 & 22 \\
Upper optimal temperature $\left({ }^{\circ} \mathrm{C}\right)$ & DV2 & 37 \\
Limiting high temperature $\left({ }^{\circ} \mathrm{C}\right)$ & DV3 & 40 \\
\hline PDD & & 476 \\
\hline Moisture & & \\
\hline Limiting low soil moisture & SM0 & 0.05 \\
Lower optimal soil moisture & SM1 & 0.3 \\
Upper optimal soil moisture & SM2 & 0.9 \\
Limiting high soil moisture & SM3 & 1.3 \\
\hline
\end{tabular}


Table 1. Cont

\begin{tabular}{lcc}
\hline \multicolumn{1}{c}{ Parameters } & Code & Optimal Value \\
\hline Cold stress & & \\
\hline CS temperature threshold $\left({ }^{\circ} \mathrm{C}\right)$ & TTCS & 0 \\
CS temperature rate & THCS & -0.00447 \\
CS degree-day threshold & DTCS & 0 \\
CS degree-day rate & DHCS & 0 \\
\hline Heat stress & & \\
\hline HS temperature threshold $\left({ }^{\circ} \mathrm{C}\right)$ & TTHS & 40 \\
HS temperature rate & THHS & 0.0018 \\
\hline Dry stress & & \\
\hline DS threshold & SMDS & 0.05 \\
DS rate & HDS & -0.0025 \\
\hline Wet stress & \\
\hline WS threshold & SMWS & 1.3 \\
WS threshold & HWS & 0.01 \\
\hline
\end{tabular}

\subsection{CLIMEX Operation for Assessing Climatic Suitability and Seasonal Occurrence}

The Compare Location function in the CLIMEX model was used quantitatively to evaluate the potential distribution of the red imported fire ant in South Korea as a function of climatic suitability. By connecting a regional climate with the biological characteristics of a target species, the CLIMEX model produces the Ecoclimatic Index (EI) that provides a representative assessment of climatic suitability. The EI ranges from 0 to 100, with a value greater than 20 indicating that the area is highly suitable for species establishment. In this study, we specifically categorized regions by applying the following EI ranges: impossible $(\mathrm{EI} \leq 2)$, unsuitable $(2<\mathrm{EI} \leq 10)$, moderately suitable $(10<\mathrm{EI} \leq 20)$, and ideal climates $(E I>20)$ for red imported fire ant survival. In addition, the occurrence time and duration were predicted by the Growth Index (GI), which evaluates the potential population growth under favorable climate conditions [33]. Since GI addresses how the potential growth of a species changes over 365 days, the occurrence time of the red imported fire ant was evaluated from changes in GI values and predicted to occur during the time with GI over zero [53]. Therefore, we analyzed changes in GI to predict the time of occurrence for 74 cities in South Korea and combined the results with climatic suitability to identify areas at risk for red imported fire ant invasion.

\subsection{Constructing the Map for Covered Cultivation Areas}

It is reported that the red imported fire ant invades artificial structures used for cultivating and storing food and horticultural crops to overcome unfavorable conditions [25]. To consider the effect of agricultural structures, we constructed a map recording the number of covered cultivation areas (e.g., greenhouse). For this purpose, we obtained the land-cover map provided by the National Environment Information Network System (NEINS) of the Korea Environment Institute [54]. The land-cover map is composed of complex images acquired by satellites and classified into physical conditions of the earth's surface such as agricultural areas, forests, grassland, and concrete pavement. From the land-cover map, covered cultivation areas, being a subclass of agricultural areas, was extracted by using ArcMap. We then converted extracted data from the polygon to raster format and classified the data according to the number of covered cultivation areas in each administrative district. The final map recorded areas by categories of 50, 100, 200, 400, and 800 . 


\section{Results and Discussion}

\subsection{Prediction of Climatic Suitability and Seasonal Occurrence under the Current Climate}

Quantitative evaluation of the climatic suitability of the red imported fire ant in South Korea was performed and recorded on the map shown in Figure 1A. The overall results indicate that 54 of the 74 cities $(73 \%)$ are inhospitable to the red imported fire ant, while five cities $(7 \%)$ have little climatic suitability. The red imported fire ant is known to be suited for tropical climates with an extreme low-temperature isotherm of $-17.8^{\circ} \mathrm{C}$ [23]; thus, relatively low climatic suitability was expected. Eleven cities (15\%) have EI values between 10 and 20, including Pusan, Changwon, Daegu, Gangneung, Gwangju, and Yeosu, suggesting that a relatively higher potential for accommodating red imported fire ant in those locations. Only $7 \%$ of cities (5 out of 74 ) have EI values larger than 20, suggesting a high possibility of ants' settlement after introduction. Two of them are located on Jeju Island, while Pohang, Ulsan, and Mokpo are large cities including a trading port. Cities showing high climatic suitability are located close to the sea and have ports and airports; such situation demands intensive monitoring due to a high risk of invasion [17,32]. Overall, high EI values were generally observed in cities adjacent to the sea, suggesting that introduction of red imported fire ant by ship could result in their distribution into the corresponding areas because of favorable climate [55]. This is confirmed by the way red imported fire ant was introduced to the Southern US from South America; they incidentally infiltrated the cargo carried by ships and then rapidly spread throughout the US [30]. Red imported fire ant in Taiwan, China, and Australia was also thought to have been introduced from the US by infested cargo, suggesting that trade to a specific area with favorable climate is a major route of red imported fire ant invasion [30]. The first reported introduction of red imported fire ant in South Korea was from a harbor in Busan where the EI value is larger than 10, with an ant of the same species as those found in the US [56]. This case serves as a reminder that trade cities with similar climate and population movement by tourism and business trip are at a high risk of new species introduction [57-59]. Considering these criteria, Mokpo, Pohang, Ulsan, and Jeju are areas with the highest probability of invasion of red imported fire ant.

Estimation of a likely occurrence time was performed based on GI in the cities with the EI larger than 20 (Sutherst and Maywald) [33] (Figure 1B). As previously mentioned, Jeju (two cities), Ulsan, Mokpo, and Pohang are densely populated cities with active human migration and international trade, and consequently are at a high risk for red imported fire ant invasion. Once red imported fire ant is introduced and settled in these areas, they are expected to be active from early May to late October but can be present from the end of March to mid-November in some areas, including Ulsan. Specifically, Jeju was predicted to have high red imported fire ant activity between June and September, a high-tourism period, suggesting a large potential for invasion [60,61]. For metropolitan Ulsan, the third-largest logistics hub in South Korea (accounting for 15.1\% of total trade volume), active trade may result in the artificial introduction of the red imported fire ant and its rapid dispersion. In addition, analysis of activity periods through GI predicted that Ulsan would show the longest period of ant activity. The volume of trade in the port of Ulsan does not change significantly from month to month, but the volume of trade through the port was steadily increasing and reached its all-time high in 2017 [62]. Therefore, the possibility of introducing red imported fire ant into the location would be expected to show a corresponding increase, since the spread by imports is considered to be most active during the longest period of activity of the analyzed time.

The effect of host plants has been considered to be negligible on the distribution of the red imported fire ant because it is known to be an omnivorous organism, feeding on various resources [33]. These ants are known to have damaged not only crops, animals, and humans but also agricultural and electrical equipment [63]. Since ants are ectotherms and temperature regulates metabolic functions including growth and reproduction, climate is a driving factor in determining the settlement outcome once the species is introduced into a new area; hence, simulation based on meteorological data is likely reliable. Therefore, it is worthwhile to identify high-risk areas for distribution of red imported fire ant 
based on climatic suitability and seasonal occurrence. Further, because of the high possibility of human introduction of red imported fire ant into new countries [23], cities having either ports or airports with significant tourism population and trade have an increased invasion risk when combined with high climatic suitability. For example, stings from red imported fire ant are most common in summer [64], greatly affecting areas with high tourism. Consequently, cities with a high risk of ant's introduction should require intensive quarantine.

\subsection{Prediction of Future Distribution Using an RCP 8.5 Climate Change Scenario}

Changes in the potential distribution in response to climate change allow us to predict dispersion patterns after settlement. Thus, climatic suitability is quantitatively evaluated by applying an RCP 8.5 climate change scenario in South Korea. Future potential distributions were estimated by deriving EI values for the years 2040 to 2100 with a 20-year interval and projecting them onto a map of administrative districts in South Korea (Figure 2A-D). After categorizing areas into four types of suitability based on EI value, we counted the number of regions by the EI value and its change (Figure 2E). According to the projected map, the area that fire ant could inhabit was predicted to increase through climate change, and the number of areas with EI values greater than 10 tended to rapidly increase to $25(34 \%), 32(43 \%)$, and $47(63 \%)$ in 2040, 2060, and 2080, respectively. In 2100, 64 areas are predicted to have EI values greater than 10, and many of them are located inland. Among 64 suitable areas in 2100, forty-six had EI greater than 20, suggesting ideal climate for supporting red imported fire ant. Overall, high climatic suitability was observed in coastal areas first, but the suitability of inland areas increased with time. This suggests that once the red imported fire ant is introduced via port facilities in coastal areas and settles in climatically suitable areas, it can widely disperse inland with climate change. In the US, red imported fire ant spreads to the west at a rate of about 120 miles per year after their first introduction; they steadily dispersed even in Texas where the climate is less suitable than in other regions $[23,64]$. Current distribution reaches north to regions recording a minimum temperature of $-17.8^{\circ} \mathrm{C}$ and west to California, all occurring much faster than expected [64,65]. In China, Hong Kong was considered to be the initial point of invasion, with the distribution expected to reach the mainland within 10 years [66]. The red imported fire ant has also distributed through direct movement but often with human assistance $[23,40]$. It has distributed varying distances by vehicles loading timber, sod, livestock feed, and construction equipment [66,67]. Therefore, with favorable climatic conditions, the red imported fire ant is likely to invade inland regions more rapidly than expected, reaching even unexpected regions. This suggests that species distribution modeling is necessary to predict the direction of dispersion with climate and thus provide fundamental data to be used for putting in place quarantine systems and control points. 
(A)

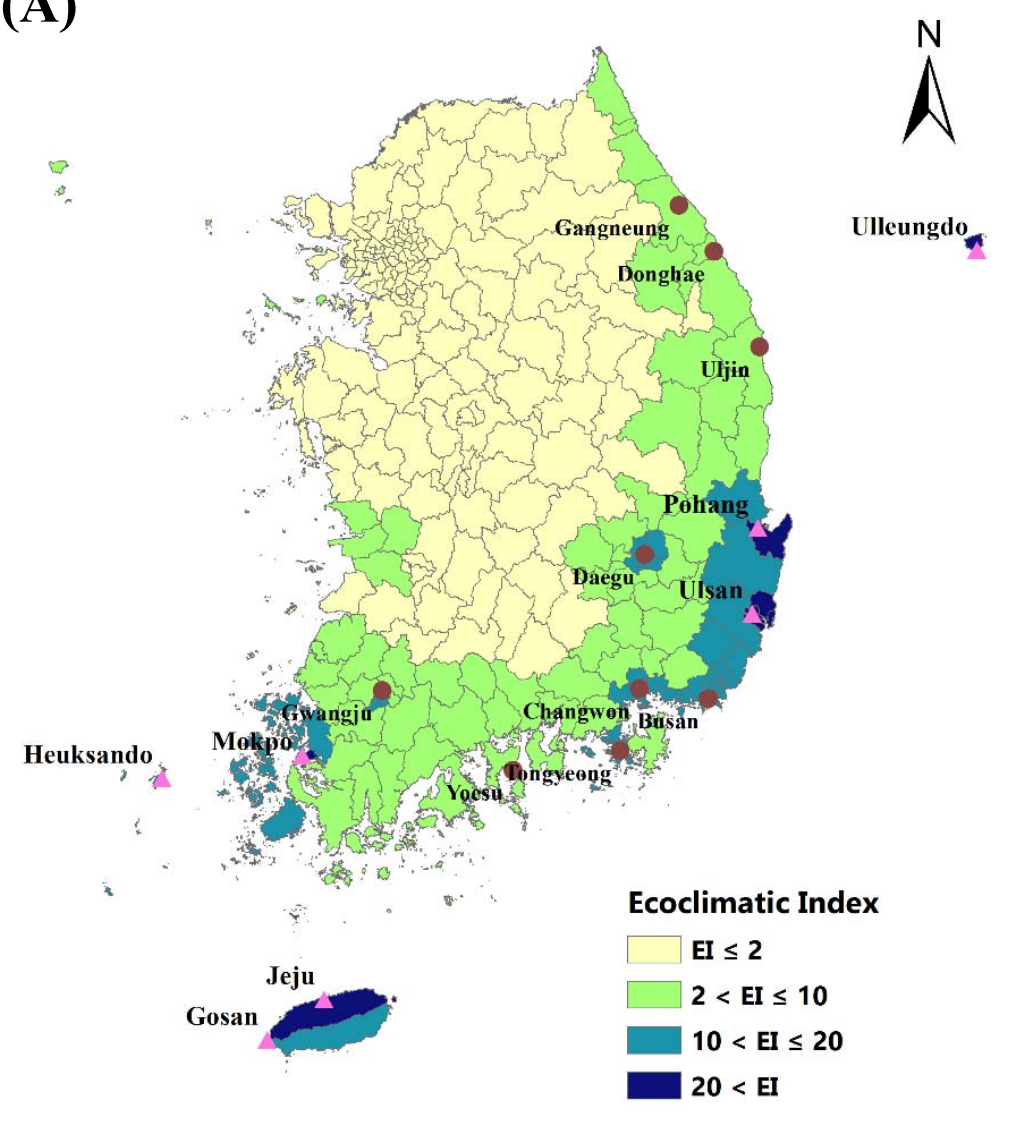

(B)

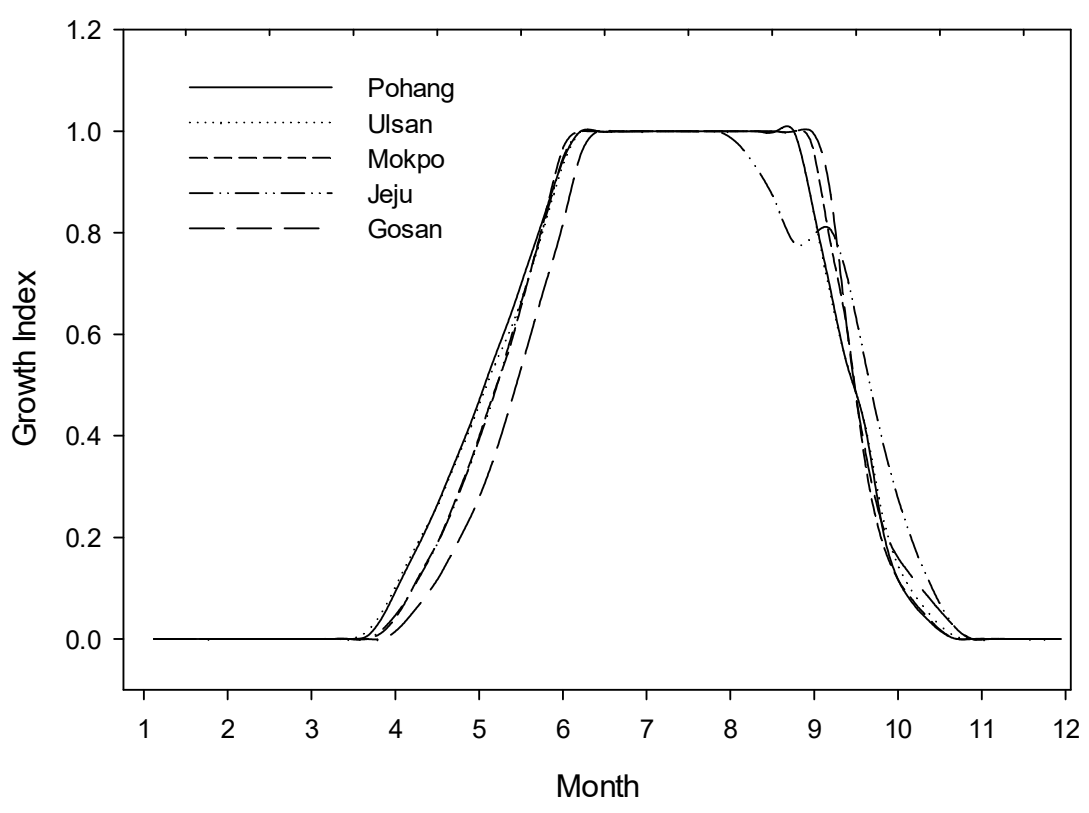

Figure 1. Map for climatic suitability represented by the Ecoclimatic Index (EI) under current climate with the main cities showing a high risk of the red imported fire ant invasion (A). Potential active seasons represented by the Growth Index in the 5 main risky cities (B). Brown circles and pink triangles mean cities with a EI value more than 10 and 20 , respectively. 
(A)

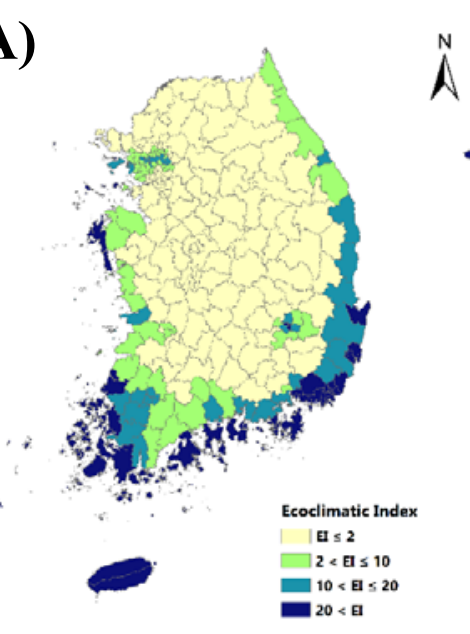

(C)

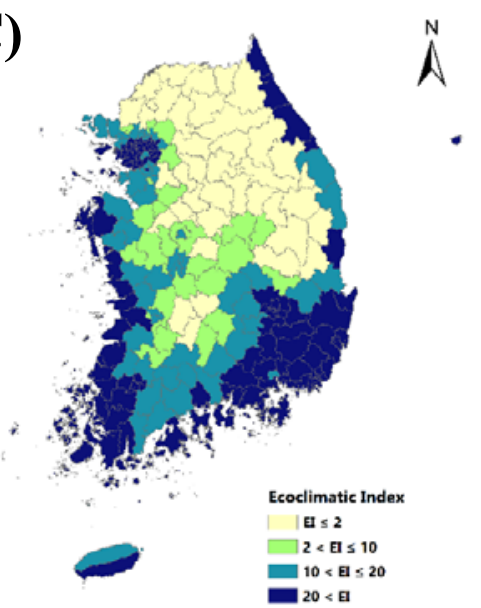

(B)

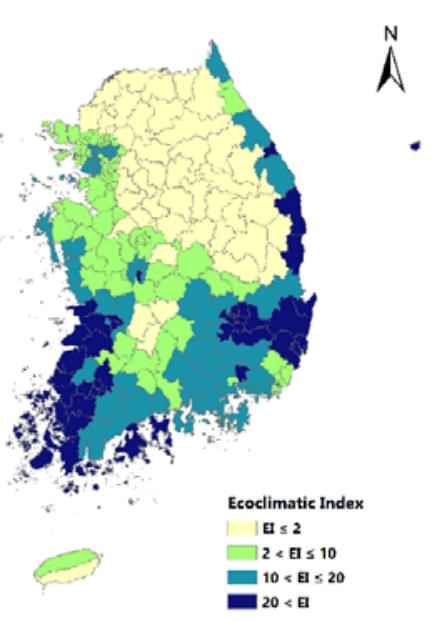

(D)

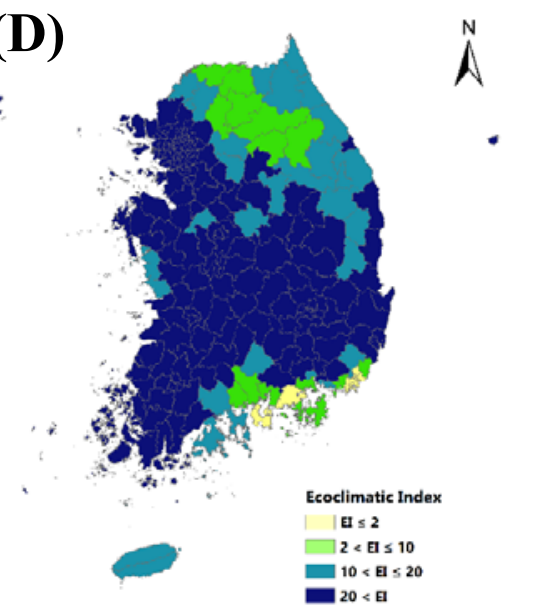

(E)

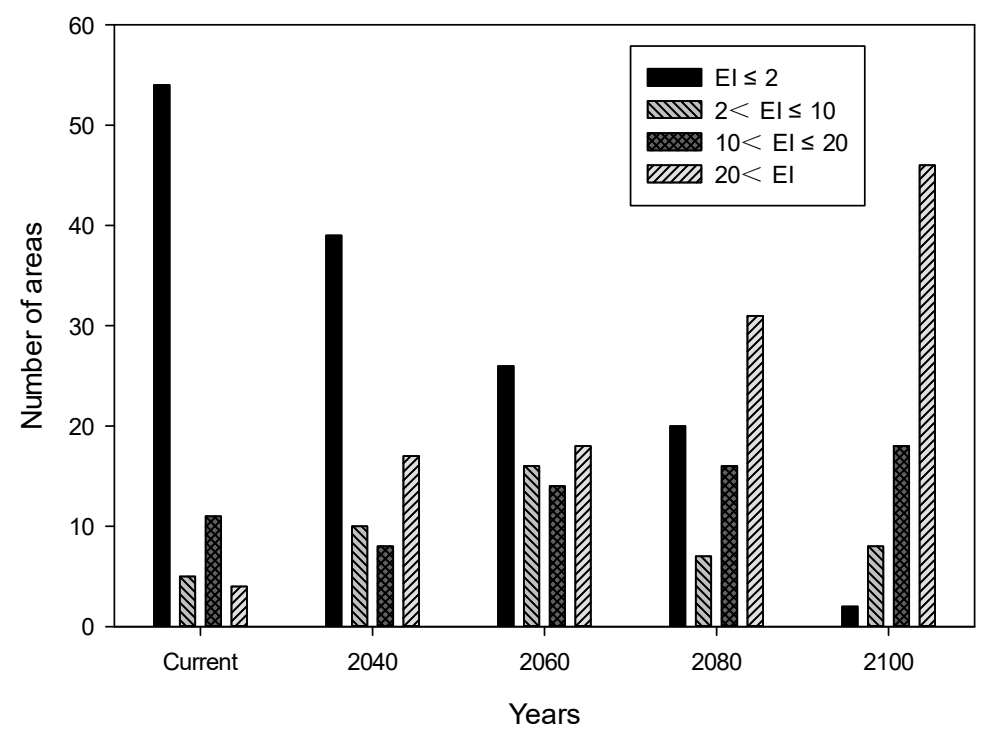

Figure 2. Predicted distribution of red imported fire ant ((A): 2040, (B): 2060, (C): 2800, (D): 2100), and changes in EI values by the number of areas and times in response to climate change (E). 


\subsection{Risk Analysis of the Red Imported Fire Ant Invasion and Dispersion by Considering Covered Cultivation Areas}

Red imported fire ant is distributed in agricultural fields and croplands in the United States and Puerto Rico, suggesting the possibilities of invasion into agricultural facilities and construction of microclimates due to dense crop canopy with water supplementation [32]. Even when overall climatic suitability was predicted to be low under the current climate, it might be possible that unfavorable conditions are altered through the introduction of covered agricultural structures where the environment is independent of the external climate. To evaluate the risk of introduction into highly concentrated covered cultivation areas, a map of covered domestic cultivation areas was constructed. Most domestic covered cultivation areas are located in the southern end of Jeju Island (Figure 3A). Areas with less than 50 of covered cultivation areas in the administrative district were excluded because the distance between covered cultivation areas was too long for the red imported fire ant to migrate under unfavorable climatic condition. Administrative areas having more than 50 such structures were marked with a red hatch and overlaid with the map of climatic suitability (Figure 3B-F). Regions with high climatic suitability but with few covered cultivation areas may cause local damage in the east coast due to increasing climate suitability along the coast. In contrast, areas with low climate suitability but with large covered cultivation areas might generate some risk due to migration from adjacent areas with high climatic suitability and entry into facilities to overcome unfavorable climate. The most dangerous areas were thought to be areas with a large number of cultivation structures and with high climatic suitability. Thus, a high possibility of establishment was expected in Jeju Island and areas near Pohang under the current climate. In 2040, climate change would expand the risk to south coast areas adjacent to a large number of covered cultivation areas. In 2060, as the potential habitat of red imported fire ant expanded inland, the risks would be highest in southern inland areas where covered cultivation areas are concentrated, while the risk of invasion into Jeju Island would be lowered due to reduced climatic suitability. In 2080, the likelihood of invasion becomes high in all covered cultivation areas except in the northern regions, but most of the covered cultivation areas are predicted to become vulnerable to red imported fire ant invasion in 2100 . In summary, five areas among 34 major covered cultivation areas of the administrative district (14\%) showed high climatic suitability. The number is expected to increase up to 11 areas (32\%) in 2040. The number of cultivation areas with high climatic suitability is to increase steadily up to $25(74 \%), 31(89 \%)$, and $34(97 \%)$ areas in 2060 , 2080, and 2100, respectively.

Plant seeds are one of the main food sources for red imported fire ant [68], suggesting that the insect could spread into agricultural facilities including greenhouses and storage areas. In addition, the introduction of red imported fire ants through the transport of manure has been recognized [67]; thus, insects could migrate into facilities with the manure used as a fertilizer. Cities along the west coast are actively involved in international trade with China where the distribution of red imported fire ant has already been confirmed [40]. Thus, even though these regions currently show low climatic suitability, the red imported fire ant could possibly disperse throughout covered cultivation areas after being introduced via the above man-assisted artificial route. Moreover, Korea-China FTA (Free Trade Agreement) [69] and the rapid spread of red imported fire ant reported in China [67] increase the risk of invasion. In fact, in 2018, the red fire ant was brought from China in containers delivered to Incheon Port. Since red imported fire ant was discovered at Busan port in 2017, the possibility of the species introduction through shipment is likely the highest [43]. The risk of damage to people working in agricultural facilities needs to be considered since red imported fire ant stings. It was reported that $30 \%$ of residents in an area inhabited by the red imported fire ant was affected. Another study found that $89 \%$ of residents living in the red imported fire ant habitat were stung each year [23,70]. Even though the toxicity of the red imported fire ant is relatively low, allergic reactions can cause serious symptoms, such as difficulty breathing, confusion and even death if adequate treatment is delayed [23]. 
(A)

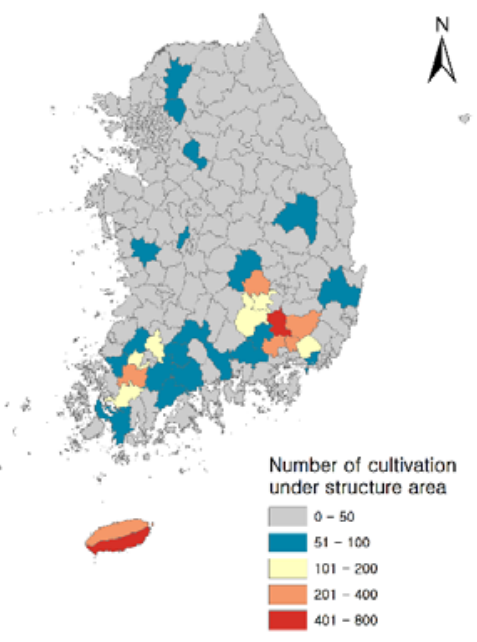

(D)

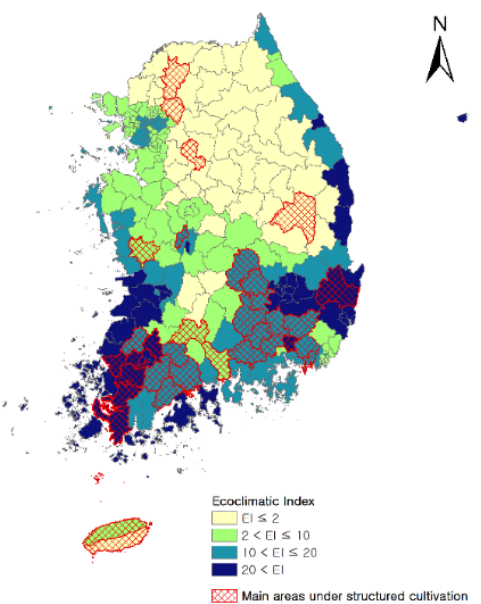

(B)

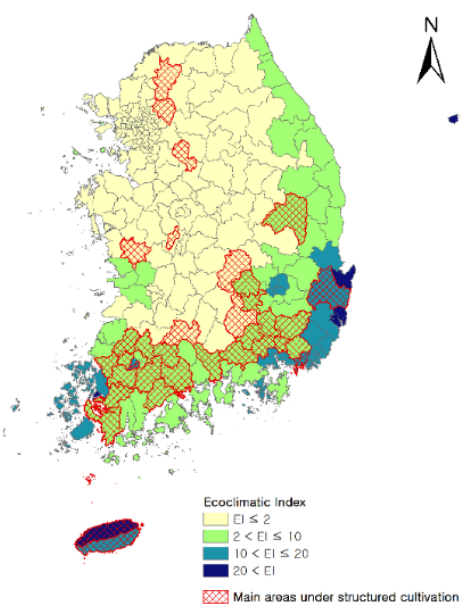

(E)

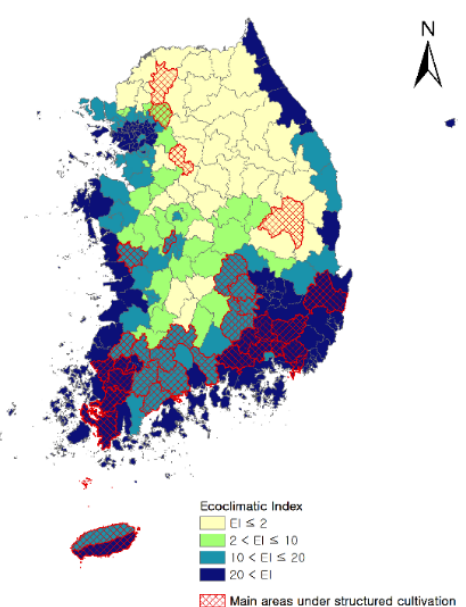

(C)

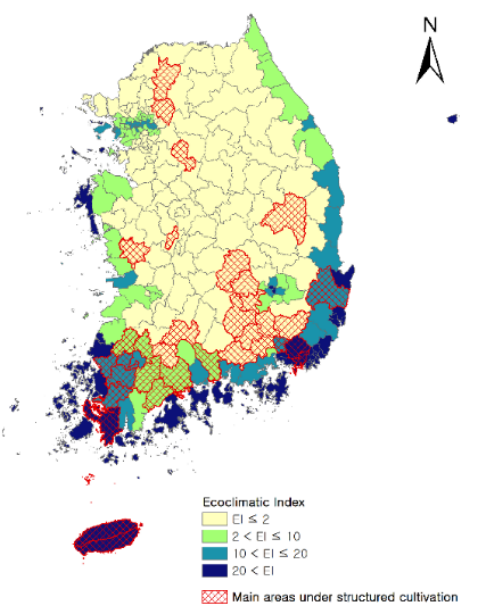

(F)

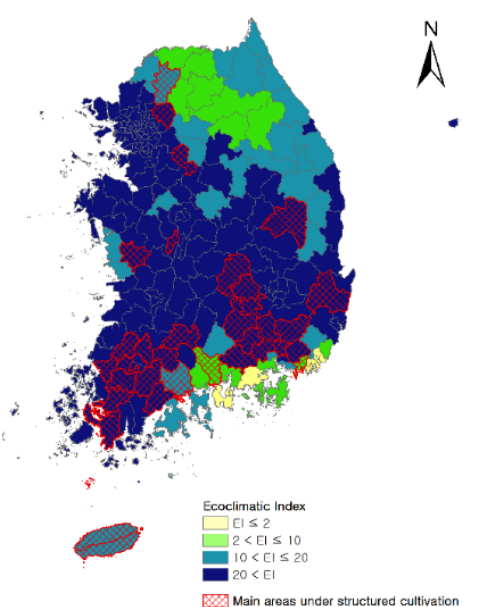

Figure 3. Map recording the number of cultivation areas under structure (A), and maps overlaid climatic suitability of the red imported fire ant and the number of cultivation areas ((B): current; (C); 2040, (D): 2060, (E): 2080, and (F): 2100). 
Overall, the areas with the highest risk were evaluated in consideration of climatic suitability, the number of covered cultivation areas, and the location of possible artificial ingress (e.g., ports and airports). As a result, Jeju and Pohang were expected to have the highest risk under the current climate, while Busan and Mokpo would be the most at risk in 2040. However, as previously mentioned, most areas in South Korea will be exposed to the threat of red imported fire ant invasion due to climate change. Finally, we summarized a list of cities exposed to a high potential for red imported fire ant invasion by comprehensively considering factors affecting its introduction (Table 2). The major areas at risk of red imported fire ant invasion in South Korea are six cities (except for Gosan) that have harbors involved in regular international trade. In the case of Busan where the climatic suitability is relatively low, sufficient risk may still exist because of the largest volume of international trade that operates in that port.

Table 2. List of most dangerous cities exposed to red imported fire ant invasion.

\begin{tabular}{ccccccc}
\hline & Jeju & \multicolumn{2}{c}{ Pohang Busan } & Ulsan & Mokpo & Gosan \\
\hline EI (current) & 40 & 34 & 16 & 29 & 34 & 38 \\
Areas cultivation & 241 & 56 & 99 & 56 & 172 & 717 \\
under structures & & & & & & $\bigcirc$ \\
Port & $\bigcirc$ & $\bigcirc$ & $\bigcirc$ & $\bigcirc$ & $\bigcirc$ & $\mathrm{X}$ \\
Airport & $\bigcirc$ & $\bigcirc$ & $\bigcirc$ & $\bigcirc$ & $\bigcirc$ & $\mathrm{X}$ \\
International trades & $\bigcirc$ & $\bigcirc$ & $\bigcirc$ & $\bigcirc$ & $\bigcirc$ & \\
\hline
\end{tabular}

All the cities are marked in Figure 1A.

We finally would like to indicate the modeling itself. The developed model was used to evaluate the climatic suitability of the red imported fire ant in South Korea. For the reliable prediction, we estimated parameter values based on a previous study [34] and refined them to generate the best fit with the actual distribution obtained from a public database. The current model could produce distributions in Arizona and New Mexico in the United States where the distribution was confirmed. Since there is a time difference between previous and current predictions this suggests that the red imported fire ant have continuously expanded its habitat. Even though the current model updated the parameter values to represent the actual distribution, it should be noted that the model depends on the distribution database that we used in estimating parameter values; thus, uncertainty in the distribution data could result in uncertainty in the model prediction. The actual field survey may help reduce uncertainty caused by distribution data. However, it is only applicable to a limited area and requires significant time, cost, and labor. As an alternative to overcome the weakness caused by the distribution uncertainty, an ensemble modeling, which integrate more than two different modeling techniques can be used [71,72].

\section{Conclusions}

This study developed a CLIMEX-based species-distribution model for predicting the current potential risk of invasion by the red imported fire ant and evaluated dispersion possibility with consideration of cultivating areas under cover. Current climatic suitability was relatively high in Jeju Island and some port cities along the southern coast where seasonal occurrence would be high in summer. Climate change is expected to make inland areas a more suitable habitat for the ant, indicating the likely direction of dispersion in South Korea. In addition, there will be a high probability of spread when the red imported fire ant penetrates into agricultural facilities after being introduced through ports into areas of high climate suitability. The red imported fire ant is notorious for causing widespread damage to local agriculture and ecosystem, its ability to adapt to poor circumstances, and its rapid rate of dispersion to new areas via various routes. Thus, the importance of early control and prevention of ant's invasion should be noted. 
Author Contributions: Conceptualization, J.-H.L., H.-S.L., S.J., and W.-H.L.; Formal analysis, D.-h.B., and W.-H.L.; Funding acquisition, S.J.; Investigation, H.-S.L., and Y.P.; Methodology, D.-h.B., and W.-H.L.; Project administration, J.-H.L., and H.-S.L.; Resources, J.-H.L., and Y.P.; Software, D.-h.B., and W.-H.L.; Supervision, S.J., and W.-H.L.; Validation, D.-h.B.; Writing—original draft, D.-h.B., and W.-H.L.; Writing—review and editing, W.-H.L. All authors have read and agreed to the published version of the manuscript.

Funding: This research was supported by a fund (Project name: Species distribution modeling for two invasive fire ants (Solenopsis invicta and S. geminata)) by Research of Animal and Plant Quarantine Agency, South Korea.

Conflicts of Interest: The authors declare no conflict of interest.

\section{References}

1. Pearson, R.G.; Dawson, T.P. Predicting the impacts of climate change on the distribution of species: Are bioclimate envelope models useful? Glob. Ecol. Biogeogr. 2003, 12, 361-371. [CrossRef]

2. Andrewartha, H.G.; Birch, L.C. The Distribution and Abundance of Animals; University of Chicago Press: Chicago, IL, USA, 1954.

3. Van Klinken, R.D.; Lawson, B.E.; Zalucki, M.P. Predicting invasions in Australia by a Neotropical shrub under climate change: The challenge of novel climates and parameter estimation. Glob. Ecol. Biogeogr. 2009, 18, 688-700. [CrossRef]

4. Shabani, F.; Kumar, L. Sensitivity analysis of CLIMEX parameters in modeling potential distribution of Phoenix dactylifera L. PLoS ONE 2014, 9, e94867. [CrossRef] [PubMed]

5. Byeon, D.H.; Jung, S.; Lee, W.H. Review of CLIMEX and MaxEnt for studying species distribution in South Korea. J. Asia Pac. Biodivers. 2018, 11, 325-333. [CrossRef]

6. Porter, J.H.; Parry, M.L.; Carter, T.R. The potential effects of climatic change on agricultural insect pests. Agric. For. Meteorol. 1991, 57, 221-240. [CrossRef]

7. Jeschke, J.M.; Strayer, D.L. Usefulness of bioclimatic models for studying climate change and invasive species. Ann. N. Y. Acad. Sci. 2008, 1134, 1-24. [CrossRef]

8. Austin, M.P.; Van Niel, K.P. Improving species distribution models for climate change studies: Variable selection and scale. J. Biogeogr. 2011, 38, 1-8. [CrossRef]

9. Peterson, A.T. Predicting the geography of species' invasions via ecological niche modeling. Q. Rev. Biol. 2003, 78, 419-433. [CrossRef]

10. Beaumont, L.J.; Hughes, L.; Poulsen, M. Predicting species distributions: Use of climatic parameters in BIOCLIM and its impact on predictions of species' current and future distributions. Ecol. Model. 2005, 186, 251-270. [CrossRef]

11. Guisan, A.; Thuiller, W. Predicting species distribution: Offering more than simple habitat models. Ecol. Lett. 2005, 8, 993-1009. [CrossRef]

12. Kriticos, D.J.; Maywald, G.F.; Yonow, T.; Zurcher, E.J.; Herrmann, N.I.; Sutherst, R.W. CLIMEX Version 4: Exploring the Effects of Climate on Plants, Animals and Diseases; CSIRO: Canberra, Australia, 2015.

13. Jung, J.M.; Lee, W.H.; Jung, S. Insect distribution in response to climate change based on a model: Review of function and use of CLIMEX. Entomol. Res. 2016, 46, 223-235. [CrossRef]

14. Park, J.J.; Mo, H.H.; Lee, G.S.; Lee, S.E.; Lee, J.H.; Cho, K. Predicting the potential geographic distribution of Thrips palmi in Korea, using the CLIMEX model. Entomol. Res. 2014, 44, 47-57. [CrossRef]

15. Kim, J.; Jung, H.; Park, Y.H. Predicting Potential Distribution of Monochamus alternatus Hope responding to Climate Change in Korea. Korean J. Appl. Entomol. 2016, 55, 501-511. [CrossRef]

16. Park, J.J.; Jung, C. Risk prediction of the distribution of invasive hornet, Vespa velutina nigrothorax in Korea using CLIMEX model. Korean J. Apic. 2016, 31, 293-303. [CrossRef]

17. Jung, J.M.; Jung, S.; Ahmed, M.R.; Cho, B.K.; Lee, W.H. Invasion risk of the yellow crazy ant (Anoplolepis gracilipes) under the Representative Concentration Pathways 8.5 climate change scenario in South Korea. J. Asia Pac. Biodivers. 2017, 10, 548-554. [CrossRef]

18. Jung, J.M.; Jung, S.; Byeon, D.H.; Lee, W.H. Model-based prediction of potential distribution of the invasive insect pest, spotted lanternfly Lycorma delicatula (Hemiptera: Fulgoridae), by using CLIMEX. J. Asia Pac. Biodivers. 2017, 10, 532-538. [CrossRef]

19. Jung, J.M.; Lee, J.W.; Kim, C.J.; Jung, S.; Lee, W.H. CLIMEX-based analysis of potential geographical distribution of Aedes albopictus and Aedes aegypti in South Korea. J. Biosyst. Eng. 2017, 42, 217-226. 
20. Byeon, D.H.; Jung, S.; Mo, C.; Lee, W.H. Effectiveness of sensitivity analysis for parameter selection in CLIMEX modeling of Metcalfa pruinosa Distribution. J. Biosyst. Eng. 2018, 43, 410-419.

21. Pachauri, R.K.; Allen, M.R.; Barros, V.R.; Broome, J.; Cramer, W.; Christ, R.; Church, J.A.; Clarke, L.; Dahe, Q.; Dasgupta, P.; et al. Climate Change 2014: Synthesis Report. Contribution of Working Groups I, II and III to the Fifth Assessment Report of the Intergovernmental Panel on Climate Change; IPCC: Geneva, Switzerland, 2014; p. 151.

22. Choi, Y.S.; Hwang, I.S.; Kang, T.J.; Lim, J.R.; Choe, K.R. Oviposition characteristics of Ricania sp. (Homoptera: Ricaniidae), a new fruit pest. Korean J. Appl. Entomol. 2011, 50, 367-372. [CrossRef]

23. Vinson, S.B. Insect life: Invasion of the red imported fire ant (Hymenoptera: Formicidae). Am. Entomol. 1997, 43, 23-39. [CrossRef]

24. Banks, W.A.; Adams, C.T.; Lofgren, C.S. Damage to young citrus trees by the red imported fire ant (Hymenoptera: Formicidae). J. Econ. Entomol. 1991, 84, 241-246. [CrossRef]

25. Morrison, J.E., Jr.; Williams, D.F.; Oi, D.H.; Potter, K.N. Damage to dry crop seed by red imported fire ant (Hymenoptera: Formicidae). J. Econ. Entomol. 1997, 90, 218-222. [CrossRef]

26. Adams, C.T.; Banks, W.A.; Lofgren, C.S. Red imported fire ant (Hymenoptera: Formicidae): Correlation of ant density with damage to two cultivars of potatoes (Solanum tuberosum L.). J. Econ. Entomol. 1988, 81, 905-909. [CrossRef]

27. Jemal, A.; Hugh-Jones, M. A review of the red imported fire ant (Solenopsis invicta Buren) and its impacts on plant, animal, and human health. Prev. Vet. Med. 1993, 17, 19-32. [CrossRef]

28. Solley, G.O.; Vanderwoude, C.; Knight, G.K. Anaphylaxis due to red imported fire ant sting. Med. J. Aust. 2002, 176, 521-523. [CrossRef] [PubMed]

29. Williams, D.F.; Collins, H.L.; Oi, D.H. The red imported fire ant (Hymenoptera: Formicidae): An historical perspective of treatment programs and the development of chemical baits for control. Am. Entomol. 2001, 47, 146-159. [CrossRef]

30. Ascunce, M.S.; Yang, C.C.; Oakey, J.; Calcaterra, L.; Wu, W.J.; Shih, C.J.; Goudet, J.; Ross, K.G.; Shoemaker, D. Global invasion history of the fire ant Solenopsis invicta. Science 2011, 331, 1066-1068. [CrossRef]

31. Korzukhin, M.D.; Porter, S.D.; Thompson, L.C.; Wiley, S. Modeling temperature-dependent range limits for the fire ant Solenopsis invicta (Hymenoptera: Formicidae) in the United States. Environ. Entomol. 2001, 30, 645-655. [CrossRef]

32. Morrison, L.W.; Porter, S.D.; Daniels, E.; Korzukhin, M.D. Potential global range expansion of the invasive fire ant, Solenopsis invicta. Biol. Invasions 2004, 6, 183-191. [CrossRef]

33. Sutherst, R.W.; Maywald, G. A climate model of the red imported fire ant, Solenopsis invicta Buren (Hymenoptera: Formicidae): Implications for invasion of new regions, particularly Oceania. Environ. Entomol. 2005, 34, 317-335. [CrossRef]

34. Sung, S.; Kwon, Y.S.; Lee, D.K.; Cho, Y. Predicting the potential distribution of an invasive species, Solenopsis invicta Buren (Hymenoptera: Formicidae), under climate change using species distribution models. Entomol. Res. 2018, 48, 505-513. [CrossRef]

35. Callcott, A.M.A.; Collins, H.L. Invasion and range expansion of imported fire ants (Hymenoptera: Formicidae) in North America from 1918-1995. Fla. Entomol. 1996, 79, 240-251. [CrossRef]

36. Buren, W.F.; Allen, G.E.; Whitcomb, W.H.; Lennartz, F.E.; Williams, R.N. Zoogeography of the imported fire ants. J. N. Y. Entomol. Soc. 1974, 82, 113-124.

37. Shoemaker, D.D.; Ross, K.G.; Arnold, M. Genetic structure and evolution of a fire ant hybrid zone. Evolution 1996, 50, 1958-1976. [CrossRef] [PubMed]

38. Ross, K.G.; Shoemaker, D.D. Species delimitation in native South American fire ants. Mol. Ecol. 2005, 14, 3419-3438. [CrossRef] [PubMed]

39. Moloney, S.; Vanderwoude, C. Red Imported Fire Ants: A threat to eastern Australia's wildlife? Ecol. Manag. Restor. 2002, 3, 167-175. [CrossRef]

40. Zeng, L.; Lu, Y.; He, X.; Zhang, W.; Liang, G. Identification of red imported fire ant, Solenopsis invicta, to invade mainland China and infestation in Wuchuan, Guangdong. Chin. Bull. Entomol. 2005, 42, 144-148.

41. Bissmire, S. Red imported fire ants found at Whirinaki. Biosecurity 2006, 69, 6.

42. Zhang, R.; Li, Y.; Liu, N.; Porter, S.D. An overview of the red imported fire ant (Hymenoptera: Formicidae) in mainland China. Fla. Entomol. 2007, 90, 723-731. [CrossRef]

43. Lyu, D.; Lee, H. The red imported fire ant, Solenopsis invicta Buren (Hymenoptera: Formicidae: Myrmicinae) discovered in Busan sea port, Korea. Korean J. Appl. Entomol. 2017, 56, 437-438. 
44. CABI (Centre for Agriculture and Bioscience International). Available online: https://www.cabi.org/ISC/ datasheet/50569 (accessed on 24 October 2018).

45. GBIF (Global Biodiversity Information Facility). Available online: https://www.gbif.org/species/5035230 (accessed on 8 September 2018).

46. Porter, S.D. Impact of temperature on colony growth and developmental rates of the ant, Solenopsis invicta. J. Insect Physiol. 1988, 34, 1127-1133. [CrossRef]

47. Lu, Y.; Wang, L.; Zeng, L.; Xu, Y. The effects of temperature on the foraging activity of red imported fire ant workers (Hymenoptera: Formicidae) in South China. Sociobiology 2014, 59, 573-583. [CrossRef]

48. Vogt, J.T.; Appel, A.G. Standard metabolic rate of the fire ant, Solenopsis invicta Buren: Effects of temperature, mass, and caste. J. Insect Physiol. 1999, 45, 655-666. [CrossRef]

49. Vogt, J.T.; Smith, W.A.; Grantham, R.A.; Wright, R.E. Effects of temperature and season on foraging activity of red imported fire ants (Hymenoptera: Formicidae) in Oklahoma. Environ. Entomol. 2003, 32, 447-451. [CrossRef]

50. Xu, Y.J.; Zeng, L.; Lu, Y.Y.; Liang, G.W. Effect of soil humidity on the survival of Solenopsis invicta Buren workers. Insectes Sociaux 2009, 56, 367-373. [CrossRef]

51. Drees, B.M.; Summerlin, B.; Vinson, S.B. Foraging activity and temperature relationship for the red imported fire ant. Southwest. Entomol. 2007, 32, 149-155. [CrossRef]

52. Morrison, L.W.; Korzukhin, M.D.; Porter, S.D. Predicted range expansion of the invasive fire ant, Solenopsis invicta, in the eastern United States based on the VEMAP global warming scenario. Divers. Distrib. 2005, 11, 199-204. [CrossRef]

53. Zalucki, M.P.; Shabbir, A.; Silva, R.; Adamson, D.; Shu-Sheng, L.; Furlong, M.J. Estimating the economic cost of one of the world's major insect pests, Plutella xylostella (Lepidoptera: Plutellidae): Just how long is a piece of string? J. Econ. Entomol. 2012, 105, 1115-1129. [CrossRef]

54. KEI (Korea Environment Institute). Available online: https://www.kei.re.kr/eng/main.kei (accessed on 10 March 2019).

55. Wetterer, J.K. Exotic spread of Solenopsis invicta Buren (Hymenoptera: Formicidae) beyond North America. Sociobiology 2013, 60, 50-55. [CrossRef]

56. Kang, C.S. Red Imported Fire Ants on the Korean Peninsula, Queen Births 1500 Eggs a Day. Available online: https://news.joins.com/article/22801172 (accessed on 10 September 2018).

57. Passera, L. Characteristics of tramp species. In Exotic Ants: Biology, Impact, and Control of Introduced Species; Williams, D.F., Ed.; Westview Press: Boulder, CO, USA, 1994; pp. 23-43.

58. Jenkins, P.T. Free trade and exotic species introductions. Conserv. Biol. 1996, 10, 300-302. [CrossRef]

59. GISD (Global Invasive Species Database). 'Anoplolepis Gracilipes', Global Invasive Species Database, IUCN SSC ISSG, Compiled by O’Dowd, D. Available online: www.issg.org/database/species/ecology.asp?si=110 (accessed on 10 September 2018).

60. Liebhold, A.M.; Work, T.T.; McCullough, D.G.; Cavey, J.F. Airline baggage as a pathway for alien insect species invading the United States. Am. Entomol. 2006, 52, 48-54. [CrossRef]

61. Roques, A. Alien forest insects in a warmer world and a globalised economy: Impacts of changes in trade, tourism and climate on forest biosecurity. N. Z. J. For. Sci. 2010, 40, S77-S94.

62. UPA (Ulsan Port Authority). Available online: https://www.upa.or.kr/main.do (accessed on 22 June 2018).

63. Lofgren, C.S.; Banks, W.A.; Glancey, B.M. Biology and control of imported fire ants. Annu. Rev. Entomol. 1975, 20, 1-30. [CrossRef] [PubMed]

64. Kemp, S.F.; Moffitt, J.E.; Williams, D.F.; Buhner II, W.A. Expanding habitat of the imported fire ant (Solenopsis invicta): A public health concern. J. Allergy Clin. Immunol. 2000, 105, 683-691. [CrossRef] [PubMed]

65. Killion, M.J.; Grant, W.E. A colony-growth model for the imported fire ant: Potential geographic range of an invading species. Ecol. Model. 1995, 77, 73-84. [CrossRef]

66. Wang, L.; Lu, Y.; Xu, Y.J.; Zeng, L. The current status of research on Solenopsis invicta Buren (Hymenoptera: Formicidae) in Mainland China. Asian Myrmecol. 2013, 5, 125-138.

67. Lu, Y.; Liang, G.; Zeng, L. Study on expansion pattern of red imported fire ant, Solenopsis invicta Buren, in South China. Sci. Agric. Sin. 2008, 41, 1053-1063.

68. Wilson, N.L.; Olive, A.D. Food habits of the imported fire ant in pasture and pine forest areas in southeastern Louisiana. J. Econ. Entomol. 1969, 62, 1268-1271. [CrossRef]

69. FTA (Free Trade Agreement). Available online: https://www.fta.go.kr (accessed on 22 June 2019). 
70. Stafford, C.T.; Hoffman, D.R.; Rhoades, R.B. Allergy to imported fire ants. South. Med. J. 1989, 82, $1520-1527$. [CrossRef]

71. Grenouillet, G.; Buisson, L.; Casajus, N.; Lek, S. Ensemble modelling of species distribution: The effects of geographical and environmental ranges. Ecography 2011, 34, 9-17. [CrossRef]

72. Lauzeral, C.; Grenouillet, G.; Brosse, S. Dealing with noisy absences to optimize species distribution models: An iterative ensemble modelling approach. PLoS ONE 2012, 7, e49508. [CrossRef] [PubMed]

(C) 2020 by the authors. Licensee MDPI, Basel, Switzerland. This article is an open access article distributed under the terms and conditions of the Creative Commons Attribution (CC BY) license (http://creativecommons.org/licenses/by/4.0/). 